\title{
Quadruple Innovation Helix and Smart Specialization: Knowledge Production and National Competitiveness
}

\author{
Elias Carayannis \\ Professor, School of Business, The George Washington University, \\ Address: 2201 G Street, NW, Duquès Hall, Washington, D.C. 20052, USA. E-mail: caraye@gwu.edu
}

\section{Evangelos Grigoroudis}

Faculty Associate Professor, School of Production Engineering and Management, Technical University of Crete. Address: University Campus, Kounoupidiana, 73100, Chania, Greece. E-mail: vangelis@ergasya.tuc.gr

\begin{abstract}
$\mathrm{I}$ nvesting more in research, innovation and entrepreneurship is at the heart of Europe 2020 and the only way to achieve smart, sustainable, and inclusive growth. Smart specialization emerges as a key element for place-based innovation policies. The paper explains the linkage between knowledge creation, innovation output and enhancing regional and national competitiveness. We present the six major steps that every nation/region should follow to establish a smart specialization strategy based on the basic principles as described in the EU Research and Innovation Strategies for Smart Specialization (RIS3), accompanied by some examples of excellence from the Nordic countries.

Special emphasis is paid to issues of applying the Quadruple Helix approach in the context of RIS3. This

concept extends the triple helix paradigm by presuming that society is a key actor in innovation processes along with academia, industry, and government. The society is frequently the end user of innovation and thus has a strong influence on the generation of knowledge and technologies via its demand and user function.

Our analysis allows concluding that a quadruple helix approach is suitable for developing smart specialization strategies despite the greater efforts this entails. There is an urgent need to reconsider measures to keep the momentum generated in the original initiative and demonstrate the value of this exercise. Furthermore, there is a growing need to measure the impact and quantify the value of smart specialization.
\end{abstract}

Keywords: Smart Specialization Strategy; InnovationProductivity-Competitiveness; Quadruple Innovation Helix; Mode 3 Knowledge; 3C's; SKARSE; RIS3

DOI: 10.17323/1995-459x.2016.1.31.42

Citation: Carayannis E., Grigoroudis E. (2016) Quadruple Innovation Helix and Smart Specialization: Knowledge Production and National Competitiveness. Foresight and STI Governance, vol. 10, no 1, pp. 31-42.

DOI: $10.17323 / 1995-459 x .2016 .1 .31 .42$ 
'Smart Specialization Strategy' means the national or regional innovation strategies which set priorities in order to build competitive advantage by developing and matching research and innovation strengths to business needs in order to address emerging opportunities and market developments in a coherent manner, while avoiding duplication and fragmentation of effort. A smart specialization strategy may take the form of, or be included in a national or regional research and innovation strategic policy framework.'

Source: [European Commission, 2014].

$\mathrm{T}$ he European Union has set out its vision for Europe's social market economy in the Europe 2020 strategy which aims at confronting structural weaknesses through progress in three mutually reinforcing priorities [European Commission, 2012]:

- Smart growth, based on knowledge and innovation;

- Sustainable growth, promoting a more resource efficient, greener and competitive economy;

- Inclusive growth, fostering a high employment economy delivering economic, social and territorial cohesion.

Investing more in research, innovation and entrepreneurship is at the heart of Europe 2020 and formed a crucial part of Europe's response to the economic crisis.

The European Union involves many different countries and regions, each with its own special ecosystem for research, development and innovation, and with a distinct economic background and industrial structure. With the aim to develop regions, the European Union is actively promoting the development of smart specialization strategies by regions. A smart specialization strategy, however, needs to differentiate between regions and cannot be formulated on a national level alone. There might be significant differences between regions dedicated for international export or agriculture for instance. Instead, different regions face varying challenges and also possess unique abilities which a smart specialization strategy needs to take into account [Midtkandal, Sorvik, 2012]. Thus, being smart is not copying other regions' great ideas, particularly if a region which is developing a specialization strategy differs significantly from the region from where the strategy originates. Essentially, the idea is to develop a strategy for one's own region based on its strengths. Smart specialization strategies can be based on existing strategies, as long as they are made for the region in question and can be empirically proven to be accurate [Foray et al., 2012].

The main aim of this paper is to explore the linkages between Innovation, Productivity and Competitiveness (IPC). Carayannis and Sagi emphasize that innovation and competitiveness are intrinsically unified; although one does not cause the other, both are necessary for competitiveness and for each other [Carayannis, Sagi, 2001]. We also explain the connection between knowledge creation, diffusion and innovation flow. According to Carayannis [Carayannis, 2001], 'Mode 3' knowledge system and Quadruple Innovation Helix models could serve as the foundation for diverse smart specialization strategies as they place a stronger focus on openness and cooperation in innovation, and in particular, the dynamically intertwined processes of co-opetition, co-evolution and co-specialization. The smart specialization approach is helping regions upgrade their research and innovation strategies based on a number of key principles including the implementation of multi-level governance. By applying a Quadruple Helix approach, regional policymakers are more likely to enable a place-based entrepreneurial process of discovery, which would then generate intensive experimentation and discoveries thus enhancing at the same time innovativeness [Carayannis et al., 2015; Gackstatter et al., 2014].

The paper proceeds as follows. The first section discusses the mode 3 knowledge production system followed by an analysis of the interconnectedness of innovation, productivity and competitiveness. Then we introduce the shift from the Triple Helix to Quadruple Innovation Model and outline how the Quadruple Helix can be an architectural innovation blueprint to support regional innovation strategymaking. The concluding section discusses the principles of smart specialization.

\section{Mode 3 Knowledge Production System}

The emerging glocalization (globalisation - localisation) frontier of converging systems, networks and sectors of innovation occurs in the context of a knowledge economy and society. It is strongly driven by increasingly complex, non-linear, and dynamic processes of knowledge creation, diffusion and use which eventually create a challenge to re-conceptualize, if not re-invent, the ways and means of knowledge production, utilization and renewal but also storage and accessibility.

Perceptions from different parts of the world and diverse human, socio-economic, technological, and cultural contexts are interwoven to generate an emerging new worldview on how specialized knowledge emerges. Such knowledge is embedded in a particular socio-technical context, and can serve as the unit 
of reference for stocks and flows of a hybrid, public/private, tacit/codified, tangible/virtual good, that represents the building block of knowledge economy, society, and policy [Guinet, Meissner, 2012].

According to [Carayannis, 2001] the 'Mode 3' model is the knowledge production system architecture that actively engages higher order learning (e.g. learning, learning to learn, learning to learn how to learn) in a multi-lateral, multi-nodal, multi-modal and multi-layered manner. Thus, the mode 3 models show the complexity of knowledge that needs many actors from government, academia, industry, and civil society to be generated and diffused. In the end, this broad range of actors results in co-opetition (competition-cooperation), co-specialization and co-evolution resource generation, allocation and appropriation processes (3C's) that cause the formation of modalities such as innovation networks and knowledge clusters (Figure 1).

Strategic Knowledge Arbitrage and Serendipity (SKARSE) are real option drivers triggered from the 3C's. Strategic knowledge serendipity refers to the unintended benefits of enabling knowledge to 'spill over' between employees, groups and functional domains ('happy accidents' in learning). More specifically, it describes the capacity to identify, recognize, access and integrate knowledge assets more effectively and efficiently to derive, develop and capture non-appropriable, defensible, sustainable and scalable pecuniary benefits, while Strategic Knowledge Arbitrage refers to the ability to distribute and use specific knowledge for applications other than the intended topic area [Meissner, 2015a]. It refers to the capacity to create, identify, reallocate, and recombine knowledge assets more effectively and efficiently to derive, develop and capture non-appropriable, defensible, sustainable and scalable pecuniary benefits.

It is broadly understood that organizations, namely firms, aim to perform as open systems which operate under conditions of substantial turbulence, risk, and uncertainty, and seek to balance stability and coherence with flexibility and change in pursuit of higher levels of efficacy and organizational sustainability [Carayannis et al., 2014]. Accordingly, firms use the 'new knowledge derived through the healthy balance between competition and cooperation involving employees and business partners' when defining their real options, which in turn are the basis for their decision making so as to reap the full benefits of the flexibility embedded in their investments. In this respect, firms consider expenditure in knowledge as investment in future activities, and options as revenues resulting from knowledge generated and eventually applied. By exercising the possible options, firms have changed the parameters of their previously temporary and stable ecosystem, adapting to an increasingly unstable environment [Proskuryakova et al., 2015; Cervantes, Meissner, 2014; Meissner, 2012].

The more unstable environment can be traced back to the increasing speed of knowledge generation and availability but also to the lower cost of knowledge generation if measured against the global number of knowledge generators, e.g. knowledge workers. As a result, co-opetition enables firms to create 'new

\section{Fig. 1. Strategic knowledge, serendipity and arbitrage: multi-modal, multi-nodal,} multi-lateral, multi-level 3C's processes

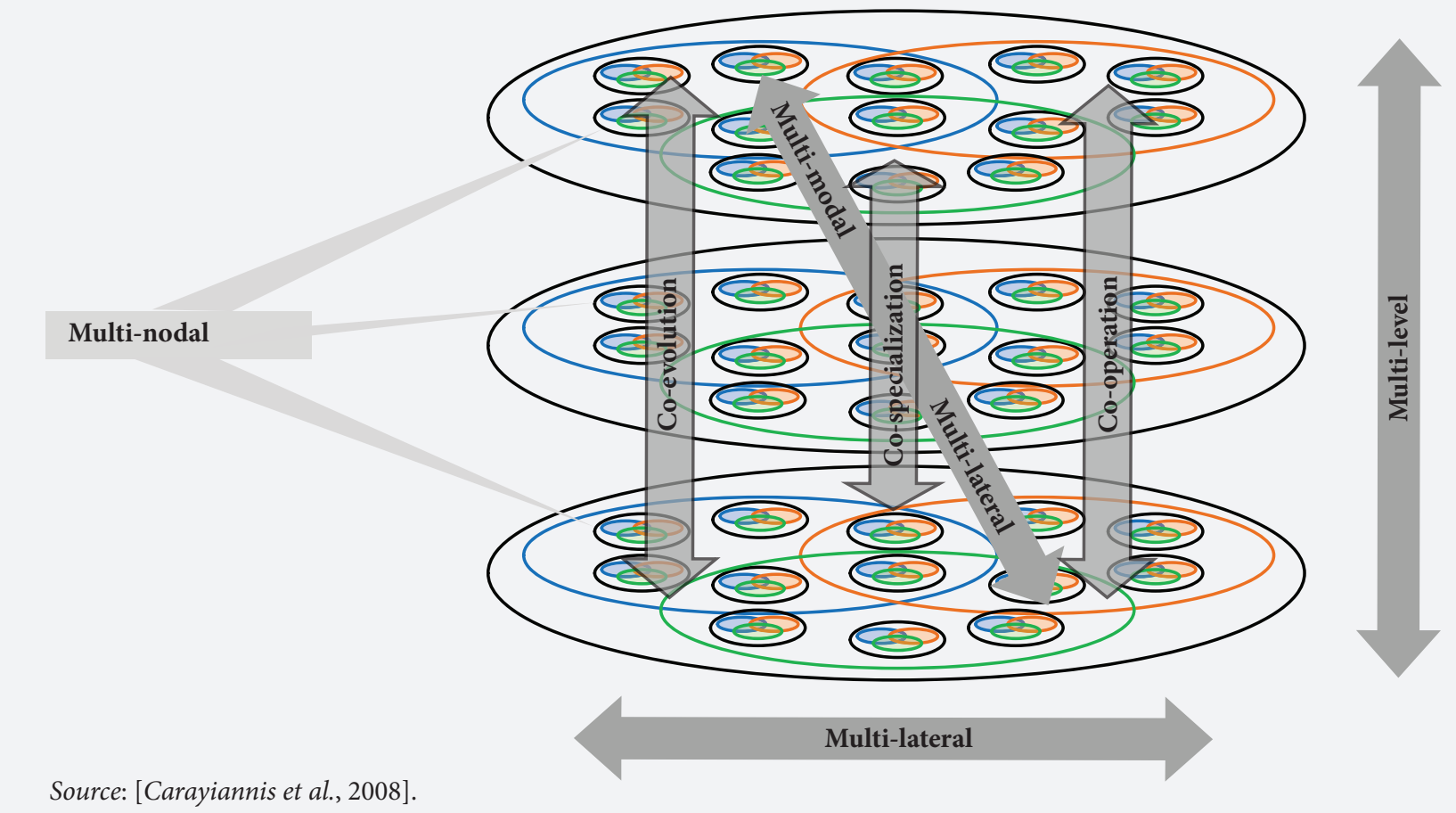


knowledge through a series of interactions and changes at various levels of the organization, spurred by the co-generation and complementary nature of that knowledge', what Carayannis and Campbell called strategic knowledge co-evolution [Carayannis, Campbell, 2009]. Furthermore, through innovation, they also undergo strategic knowledge co-specialization, 'learning and knowledge which encourages individuals or groups to expand their roles into new areas and new domains, in a complementary and mutually-reinforcing fashion.'

Nevertheless, it can be observed that innovation emerges from three critical firm level factors, i.e. Posture, Propensity and Performance. These are described in Figure 2 which uses input, process and performance indicators to structure the factors. Input indicators mainly measure resources that are put into the innovation process. These inputs include intellectual, human, and technological capital. Process indicators reflect the organizational and innovation management systems. They also embody the design of a firm's innovation system. Performance indicators (output, outcome, impact), identify the results of organizational innovation. Output indicators represent the realized short-term success of innovative activity. Indicators of this group count, for example, patent numbers, rate, number of new products, and percentage of sales with innovations. Outcome indicators represent the realized longer term success of innovative activity such as market share, firm profit margins, and firm growth rate. The impact measure indicates the sustained advantage a firm enjoys as a result of innovation.

According to [Carayannis, Sipp, 2010], innovation and SKARSE may lead to increased competitiveness. Carefully implemented innovation policies can trigger increased innovation at the firm level and trigger a chain reaction towards more macro levels and culminate in improved competitiveness. At a firm level, competitiveness focuses on company market share mainly, while national competitiveness may be considered as the capability of national economies to achieve sustained economic growth and social welfare, by efficiently allocating available resources (human and natural resources, capital) and having in place the appropriate structures, institutions, and policies. In this context, national competitiveness is defined as 'how nations create and maintain an environment which sustains the competitiveness of its enterprises' [IMD, 2003], while numerous other alternative definitions may be found in the literature.

\section{Innovation, Productivity, and Competitiveness}

Innovation-driven competitiveness is critical for sustainable economic performance in today's knowledgebased global economy. When studying innovation, productivity, and competitiveness (IPC), significant overlaps may be observed, mainly because these concepts are inherently linked [Carayannis, Grigoroudis, 2012]. Thus, researchers focus on studying their drivers and outcomes (see for example [Jansen, 2006]). Innovation indicators are frequently employed to answer these research questions. Such methods for measuring innovation include approaches based on both single (e.g. R\&D expenditures, number of patents) and composite indicators. Given that a single indicator can provide only a limited view of such a broad concept, the use of composite indicators has significantly increased in recent decades [Paas, Poltimäe, 2010]. In this context, the relevant literature reveals two major approaches:

\section{Fig. 2. Heterogeneity Dynamics - Input, Process, Output}

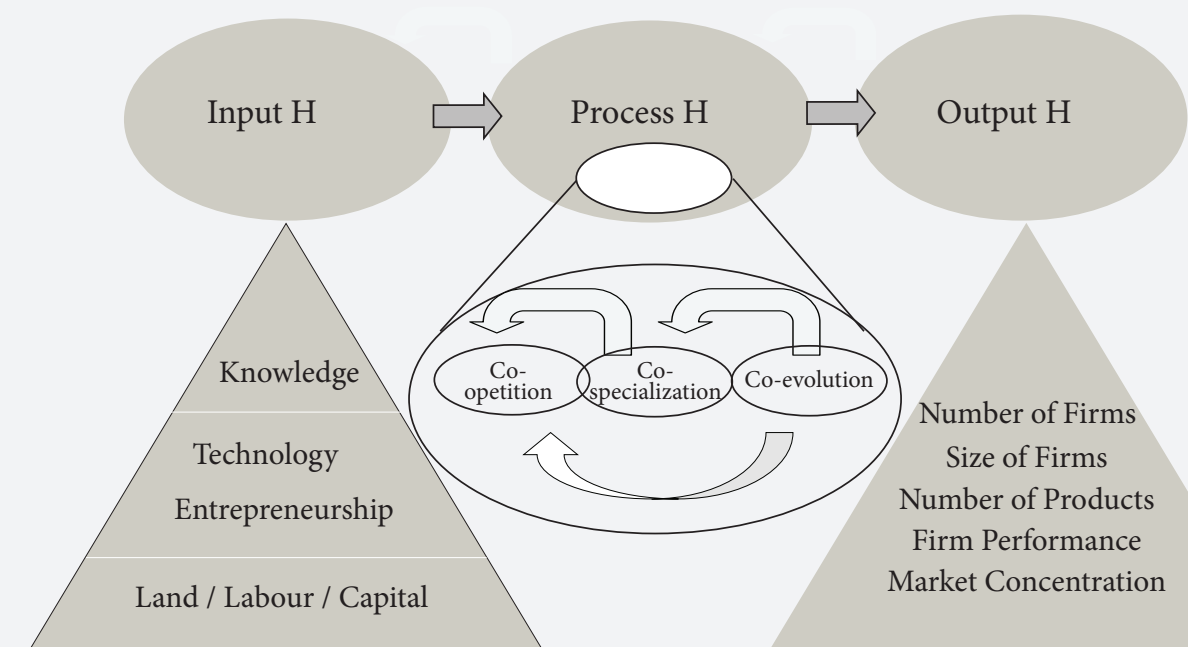

Source: [Carayiannis, Provance, 2008]. 
- Evaluation of national performance and ranking of countries;

- Analysis of National Innovation Systems.

The first approach mainly comprises comparative analyses of different aggregated innovation measures, while the second approach involves examining a single country and emphasizes the factors that may impact innovation performance. The most widely used composite innovation index is the Innovation Union Scoreboard (EIS) ${ }^{1}$. The IUS for 2015 consists of three (3) main blocks, eight (8) innovation dimensions, capturing in total 25 different indicators [Meissner, 2015b].

Productivity measurement was initially based on a production function context and linked with economic growth. Alternative productivity measures may be found in the relevant literature and these different productivity measures are classified according to the following criteria:

- Number of factors: This categorization includes single factor productivity and multifactor productivity, where a bundle of inputs is considered.

- Type of output measure: The alternative categories refer either to gross output or value added.

Many scholars argue that labour productivity is the most useful productivity measure because it is related to the most important factor of production, can be easily measured, and is a key determinant of living standards [OECD, 2001]. However, it only partially captures the different aspects of this concept, and thus multifactor productivity is usually considered. Moreover, it does not include the social dimension of labour, e.g. labour satisfaction and overall wellbeing, which has only recently come to be recognized as a determinant of labour productivity.

The concepts of productivity and competitiveness seem inherently related, given that competitiveness is considered as the capability of national economies to achieve sustained economic growth through efficiently allocating available resources. In addition, the World Economic Forum (WEF) defines competitiveness as 'the set of institutions, policies, and factors that determine the level of productivity of a country' [WEF, 2012]. Thus, in several cases, productivity is considered as the only meaningful concept of national competitiveness. As a result, Gross National Product (GNP) per capita may be used as a reliable performance index only when a single measure should be considered. The most important efforts for developing a competiveness measurement framework refer to the Global Competitiveness Index (GCI) developed by WEF and the World Competitiveness Yearbook (WCY) provided by the International Institute for Management Development (IMD).

The measurement techniques adopted by the major IPC barometers are mainly based on simple estimation techniques, since a weighted average formula is usually adopted. Composite indicators are still the best tool available for analysing such complex concepts [Paas, Poltimäe, 2010]. In addition, the interrelations among these concepts are rather strong. All these issues justify the necessity of developing new measurement frameworks that are able to study IPC composite indices in an integrated way.

Moreover, the concepts of national IPC appear to overlap and/or have significant interrelationships. The relevant literature shows that these concepts are usually jointly studied at firm, industry, or country level. In addition, several studies also include other related aspects such as creativity and entrepreneurship (see for example, [Carayannis, Gonzalez, 2003]) that increase the difficulty of analysing the linkages among IPC.

The linkage between innovation and productivity/competitiveness is relatively strong, as emphasized by numerous studies (see for example [Carayannis, Sagi, 2001]). Technology appears as a key factor which, through innovation, may influence economies of scale, the timing of processes, and the introduction of new methods, and thus affect the competitive advantage of firms. Discussing these interrelations, Carayannis and Sagi emphasize that innovation and competitiveness are intrinsically unified; although one does not cause the other, both are necessary for competitiveness and for each other [Carayannis, Sagi, 2001].

On the other hand, innovation without productivity is insufficient to produce wealth and increase national competitiveness. Thus, productivity appears inherently related with innovation and competitiveness at the country level since it is the root cause of national capital income. Consequently, although the strength of linkages between IPC may vary depending on the level of analysis, these interrelations are confirmed by numerous studies.

In the Operation Research/Management Science (OR/MS) literature, these concepts are usually studied in a cause-and-effect way, adopting a Data Envelopment Analysis (DEA) approach. A characteristic holistic approach is given by Carayannis and Sagi who argue that these linkages may be observed both horizontally and vertically, sharing factors and resources such as funding, knowledge and signals [Carayannis, Sagi, 2001, 2002]. Figure 3 presents the authors' CPI model, where national productivity results not only from national innovation programmes, but also from industrial productivity, university structures, government policies, and so forth.

${ }_{1}$ Before 2010 - European Innovation Scoreboard (EIS). 


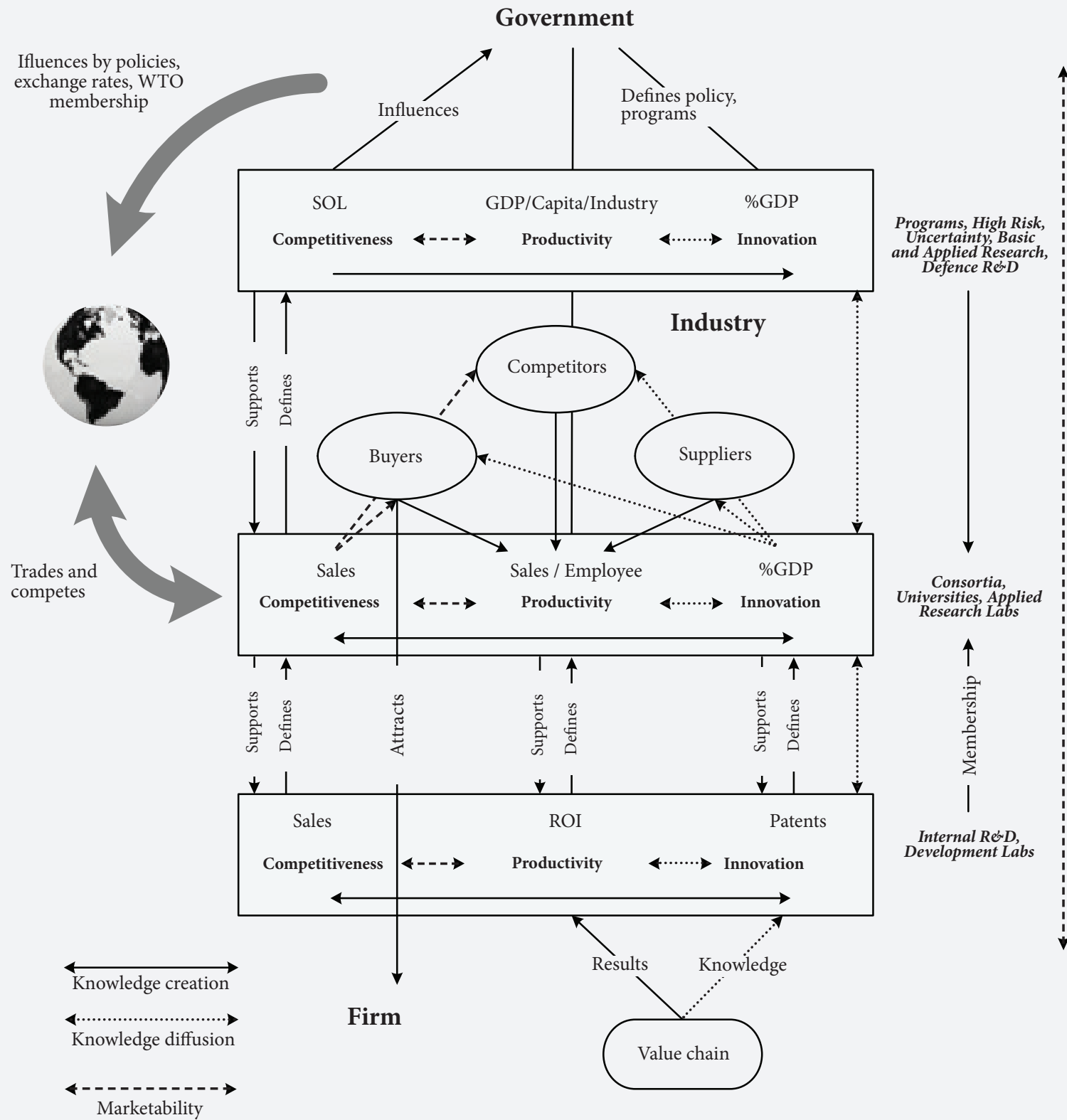

Source: [Carayiannis, Sagi, 2002].

Carayannis and Grigoroudis have estimated aggregated national innovation, productivity and competitiveness indices based on a set of relevant indicators that describe the various aspects of these concepts [Carayannis, Grigoroudis, 2012]. They assume that innovation may improve national productivity, which in turn gives the ability to compete globally. Carayannis and Grigoroudis extended their work by adopting a regression-based, multi-objective nonlinear programme (MONLP) [Carayannis, Grigoroudis, 2015]. The model's main characteristic is that it has multiple objectives, which both minimizes the estimation errors and maximizes the correlation between the aggregated IPC indices. Moreover, the MONLP model is a nonparametric approach, which means there are no assumptions about the statistical properties of the examined variables. In addition, the weights of the aggregation formula do not follow an arbitrary equal weighting scheme, but are estimated based on the previous multiple objectives. Other important advantages include the flexibility of the model to consider additional desired properties for the examined variables and its ability to perform a dynamic analysis based on complete time series data. 


\section{From Triple Helix to Quadruple Innovation Model}

European Commission promotes the role of the multi-annual Research and Innovation Strategies for Smart Specialization (RIS3). Researchers and practitioners generally agree about the importance of building research and innovation strategies based on the involvement of local and regional bodies, businesses, social partners, and other organizations. The so-called Triple Helix model is a formalized concept behind such interactive systems [Carayannis, Campbell, 2010].

The Triple Helix concept has also been used as an operational strategy for regional development and to further the knowledge-based economy [Leydesdorff, 2012]. The established Triple Helix model is a strong environment of parallel relationships between (national or regional) authorities, the wider business community (industry) and academia (including other research-focused institutions). This approach places more emphasis on the role of each one of these categories of actors in the innovation process. As noted by Leydesdorff [Leydesdorff, 2012], Triple Helix is a dynamic model and alternates between a number of bilateral or trilateral coordination spheres (Figure 4).

The Quadruple Innovation Helix bridges social ecology with knowledge production (Mode 3) and innovation. The most important constituent element of the quadruple helix - apart from an active civil society - is the resource of knowledge, which circulates between social sub-systems and hence affects innovation and know-how in a society. The Quadruple helix, therefore, visualizes the collective interaction and exchange of knowledge by means of the following four sub-systems:

- Education System - refers to academia, universities, higher education systems, and schools (human capital);

- Economic System - consists of industry/industries, firms, services, and banks (economic capital);

- Political System - formulates the direction in which the state/country is heading in the present and future, as well as the laws (political and legal capital);

- Civil Society - media based-culture integrates and combines two forms of capital: culture-based public - tradition, values etc. (social capital) and media-based public - television, internet, newspapers (capital of information).

Quadruple Helix Innovation models place a stronger focus on cooperation in innovation, and in particular, on the dynamically intertwined processes of co-opetition, co-evolution, and co-specialization within and across regional and sectoral innovation ecosystems that could serve as the foundation for diverse smart specialization strategies. The European Commission RIS3 guide outlines a set of general principles as to how S3 strategies should be developed at the regional level and recognizes the significance and need for the Quadruple Innovation Helix approach by proposing to add a fourth group to a classical Triple Helix model.

This Quadruple Helix model puts innovation users at its heart and encourages the development of innovation that are pertinent for users (civil society). Users or citizens in this context own and drive the innovation processes. Arnkil et al. maintain that the degree of user involvement could be defined as inclusive of the 'design by users' [Arnkil et al., 2010]. In line with this perspective, new innovative products, services, and solutions are developed with the involvement of users who take the lead, as well

\section{Fig. 4. A Triple helix configuration with negative and positive overlap} among the three sub-systems

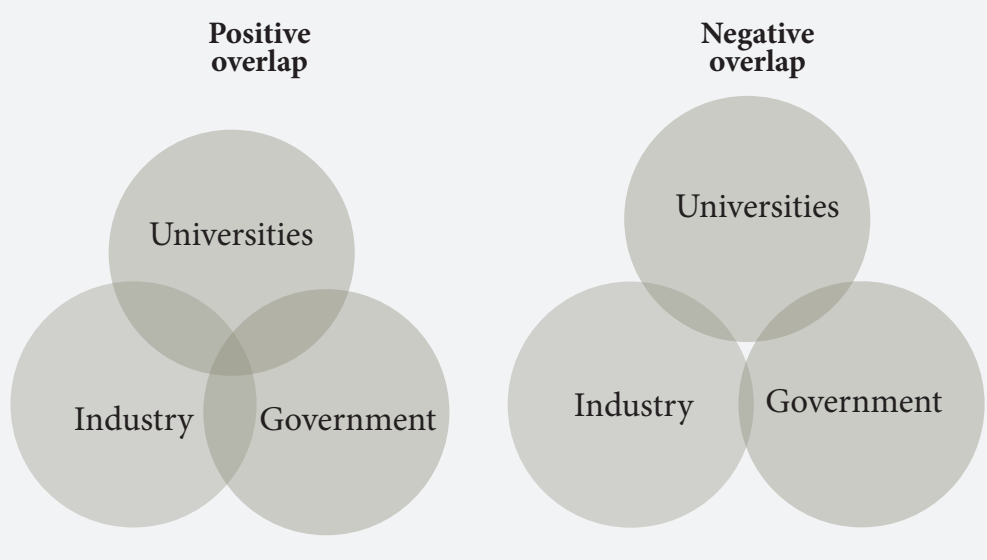

Source: [Carayiannis, Rakhmatullin, 2014]. 
as with co-developers and co-creators [Carayannis, 2001; Afonso et al., 2010]. According to this model, citizens would not only be involved in actual development work, they would also have the power to propose new types of innovations, which then connect users with their stakeholders across industry, academia, or government [Arnkil et al., 2010]. In turn, the role of actors in the other three helices would be supporting citizens in such innovation activities (e.g. providing tools, information, development forums, and skills needed by users in their innovation activities). Furthermore, industrial players and public sector stakeholders would then be able to exploit the innovations developed by citizens.

The RIS3 approach also maintains that through applying horizontal forms of multi-governance, the smart specialization approach is helping regions to upgrade their research and innovation strategies based on a number of key principles, including the implementation of multi-level governance and the Quadruple Helix approach. By applying the Quadruple Helix approach in the context of RIS3, regional policy makers are more likely to enable a place-based entrepreneurial process of discovery, which would generate intensive experimentation and discoveries. Such direct involvement of users in the innovation process is a necessary organizational counterpart to an open and user-centered innovation policy as it allows for a greater focus on understanding the underlying consumer needs [European Commission, 2012].

\section{Quadruple Helix as an Architectural Innovation Blueprint to Support RIS3}

As mentioned earlier, the Quadruple Helix concept brings together four sectoral perspectives with a focus on the institutional, regional, and operational functionalities and complementarities of these sectors in the context of the knowledge economy. The overall RIS3 context provides an appropriate operationalization framework for embedding the concept in both policy and practice.

The Quadruple Helix concept can thus serve as an architectural innovation blueprint that simultaneously engages (in a dynamically balanced top-down and bottom-up way) four sectoral perspectives (from the top-down angle of government, university, and industry, as well as from the bottom-up angle of civil society). The inter- and intra-sectoral as well as the inter- and intra-regional knowledge and learning interfaces embedded in the Quadruple Helix architectural blueprint determine its efficacy and sustainability. A combination of these four perspectives aims to conceptualize, contextualize, design, implement, and evolve smart, sustainable, and inclusive growth-driving entrepreneurship and innovation ecosystems (as well as clusters, networks and other agglomerations) at the regional level.

As the fourth pillar of the Quadruple Helix blueprint, civil society represents in a bottom-up way its collective actions and views. However, to benefit from these, policy makers should ensure mechanisms such as crowd-sourcing and crowd-funding capabilities in instruments and initiatives - are included in their regional RIS3 strategies. Embedding these elements may allow for faster, broader, cheaper, and more resilient learning, learning-to learn and learning-to-learn-how-to-learn dynamics [Carayannis, 2001]. In addition, the social networking capabilities enacted via the fourth pillar would enhance the likelihood and impact of knowledge serendipity and knowledge arbitrage events ('happy accidents'). These happy accidents would then act as triggers, catalysts, and accelerators of exploration and exploitation dynamics that could substantially empower any Quadruple Helix RIS3 strategy [Carayannis et al., 2008].

\section{Principles of Smart Specialization}

In the context of Europe 2020, smart specialization emerges therefore as a key element for place-based innovation policies and can be defined through the following five principles [Foray, Goenaga, 2013]:

1. Granularity. Smart specialization policy should concentrate on activities instead of sectors or firms. An example is the case of companies exploring the potential of nanotech to improve the operational efficiency of the pulp and paper industry. In such a case, the priority is not the pulp and paper sector overall but rather the activity involving the development of nanotech applications for this industry. Targeting the development of new activities allows the government to achieve two things through the same policy: it improves the industry's general performance, while at the same time building capabilities and expanding the knowledge base towards new fields.

2. Entrepreneurship discovery. The second novel insight is the process of entrepreneurial discovery. According to the business theory advanced by Kirzner [Kirzner, 1973], entrepreneurs are continually searching for, identifying, and evaluating new business opportunities and this process is called entrepreneurial discovery. This is equally what regional policy makers should do, focusing on activities instead of sectors. The policy makers should search for the entrepreneurial knowledge and discoveries to realize a regional or national vision. They should be able to differentiate between simple innovation and discoveries that have the potential to generate new areas of specialization and that might constitute the cornerstone of smart specialization.

3. Specialized diversification. The third principle is that the priorities emerging today will not be supported forever. After four or five years, 'new activities' are no longer new. Whether they have failed or successfully reached maturity, they should no longer be priority for the smart specialization strategy. 


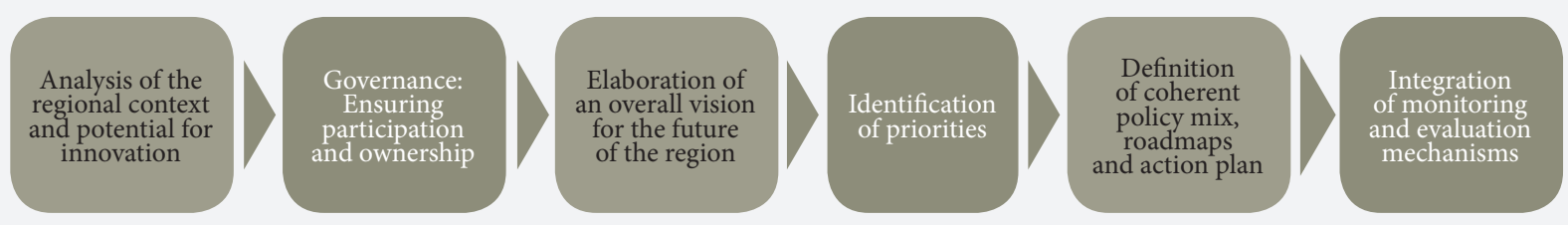

Source: [European Commission, 2012].

4. Experimentalism. The fourth new notion is experimentalism. There is no guarantee of success in any particular action; indeed, some actions will lead to failure. Smart specialization relies on the theories of experimental learning and it develops the idea of self-discovery elaborated by Hausmann and Rodrik [Hausmann, Rodrik, 2003]. According to their argument, innovation policy needs to allow for experiments in order to discover what works and what does not in a particular context. Failures must also be noted to identify success. The idea of discovery and experimentation points to the role of indicators and evaluations.

5. Inclusive strategy. Smart specialization needs to be inclusive. This does not mean that the strategy will support a project in every sector, but inclusive smart specialization means giving every sector a chance to be present in the strategy through a good project.

One way to understand smart specialization strategy is to look for information on how to create a successful strategy. Figure 5 presents a stepwise approach for RIS3 design.

\section{Examples of Excellence from the Nordic Countries}

\section{Finland - No more Nokias}

This was part of a wider reconsideration of the proper relationship between government and business. This had started in 2008, when the Finnish government shook up the universities (and created Aalto University) in an attempt to spur innovation. However, it was accelerated by Nokia's problems. Finland had become dangerously dependent on this one company: in 2000, Nokia accounted for $4 \%$ of the country's GDP. The government wanted to make the mobile-phone giant's decline as painless as possible and ensure that Finland would never again become so dependent on a single company.

The Finns created an innovation and technology agency, Tekes in 1983. They also established a venturecapital fund, Finnvera, to fund early-stage companies and help them get established. The centrepiece of their innovation system is a collection of business accelerators, part government-funded and part private enterprise funded. These operate in every significant area of business and provide potential high-growth companies with advice and support from experienced business people and angel investors.

As a result, Finland has become much more market-entrepreneur friendly. It has produced an impressive number of start-ups, including 300 founded by former Nokia employees. The country has also acquired the paraphernalia of a tech cluster, such as a celebratory blog (Arctic Startup) and a valley-related name (Arctic Valley).

Nokia's decline is the best thing that ever happened to this country. The new Finland is particularly proud of its booming video-games industry, including successful companies such as Rovio Entertainment, the maker of Angry Birds and a leading supporter of the Start-Up Sauna, and Supercell, the maker of Clash of Clans.

Nordic governments recognize that they need to encourage more entrepreneurs if they are to provide their people with high-quality jobs; they also realize they can no longer rely on large companies alone to generate business ecosystems. They are creating government agencies to promote start-ups, encouraging universities to commercialize their ideas and generate start-ups, and telling their schools to promote entrepreneurship. Many of the region's most interesting entrepreneurs operate at the low end of the tech spectrum, often to help parents deal with the practical problems of combining full-time work and family. Despite all this entrepreneurial energy, the Nordic region still finds it hard to turn start-ups into enduring companies. There are too many examples of successful entrepreneurs who have upped sticks and gone elsewhere. These include not just members of the post-war generation such as the founder of giant IKEA or the founder of Tetra Pak, but also members of the up-and-coming generation. Too many successful start-ups still choose to sell themselves to foreign multinationals rather than become local champions. 
Nevertheless, there is reason to hope that the entrepreneurial boom will also produce a new generation of global champions. One example is Rovio Entertainment, with the game Angry Birds. Having produced one big hit, most games companies would have started looking for the next one, but instead Rovio set about turning Angry Birds into a brand and extending its reach. It drew up licensing agreements with a range of companies to make Angry Birds-branded products, including toys, chocolate, and theme parks. It raised capital from outside investors such as Microsoft, which chipped in USD 42 million. Rovio now has 500 employees in Finland and had a turnover of USD 100 million in 2011 [Carayannis, Rakhmatullin, 2014].

\section{The Ostrobothnia case in Finland}

A number of attempts have been made by researchers and policy makers to evaluate different aspects of the Triple Helix model in the context of regional innovation systems, and this can indeed be extended to cover the Quadruple Helix concept.

One example is a recent exercise carried out by the Regional Council of Ostrobothnia in Finland that initiated a project to develop a method for measuring Quadruple Helix connectedness and gaps [Virkkala et al., 2014]. The results of this study would then be used as factual evidence for improving RIS multi-level governance. The S3 Guide focuses on connectedness within the Quadruple Helix approach, which it uses as a conceptual framework for good regional governance, enabling a coherent approach. In this regard, smart specialization (or S3) presents itself not just as a continuation of what we have done already under the umbrella of RIS but rather as a way of questioning existing RIS practices and removing dysfunctional policy arrangements, which hinder growth and development.

Therefore, one of the objectives of this guideline is to develop a self-assessment and evaluation tool, which could be used by regional policy makers to measure their region's progress in adopting, adapting and deploying the Quadruple Helix (QH) approach in their RIS3. The Fifth Report on Economic, Social and Territorial Cohesion prepared by the European Commission [European Commission, 2010] also suggested improving monitoring and evaluation systems across the EU to track performance and to help fine-tune efforts as needed to guarantee that pre-defined objectives are achieved in the most effective manner. This requires a clear strategic vision of what the programme aims to achieve and how success will be recognized and measured. Furthermore, it also requires a greater recourse to rigorous evaluation methods - both longitudinal and latitudinal, i.e. cross-sectoral, multi-level, and across time and space. Such evaluation approaches would help make continuous improvements when formulating and implementing QH modalities and systems within the RIS3 context [Carayannis, Rakhmatullin, 2014].

\section{Conclusion}

The paper looked at the relationship between the quadruple innovation helix and the smart specialization approaches towards knowledge production and enhancing regional and national competitiveness. National and regional innovation systems, however, go reasonably beyond the knowledge and technology production as postulated in the triple helix paradigm. The latter presumes that knowledge and technology originate from the partially overlapping activities of academia, industry, and government. In addition, the paradigm states that knowledge and technology are transferred to industry, which is ultimately the main driver of innovation. The weakness of this approach is found in the absence of the public sphere, namely society which is frequently the end user of innovation and thus has a strong influence on the generation of knowledge and technologies via its demand and user function. Therefore, the quadruple helix extends the triple helix paradigm by incorporating the societal function, which serves as a source for understanding the circulation of knowledge and technology for innovation diffusion and application. In addition, smart specialization strategies frequently developed for regional economic development and innovation competitiveness need to be extended towards the societal dimension to give them more longterm impact. Accordingly, the approaches towards developing regional strategies need to be reconsidered and at least partially redone mainly because of changing demands, in both quantitative and qualitative terms.

Regional strategies typically focus on the regional capabilities to innovate. Nevertheless, the fields of application are often markets, which are not limited to the regional dimension but are increasingly global. Hence it is essential when developing regional strategies to take account of societal developments more broadly, beyond the regional level only. In this respect, developing regional strategies becomes a more complex and challenging task for the following reasons:

- A regional development strategy typically involves SWOT analysis of regional innovation related competences. Including the societal dimension in the regional analysis requires additional competences in societal demand analysis and profound knowledge of different societal characteristics in diverse markets, which is frequently difficult to obtain at regional level;

- The value of including global societal developments into regional strategy development needs to be clearly communicated to the related regional actors and stakeholders. Frequently, this is an issue 
which is hardly recognized by regional stakeholders who believe in naturally bringing their region forward without regard for developments in other places;

- Any regional innovation strategy requires updating, which imposes additional threat on the regional actors. When such exercise is done for the first time, regional stakeholders are typically supportive and contribute; yet often, this momentum is lost when it comes to updating or repeating the exercise.

In the final analysis, we can conclude that a quadruple helix approach is suitable for developing smart specialization strategies despite the greater efforts this entails. Furthermore, there is an urgent need to reconsider measures to keep the momentum generated in the original initiative and demonstrate the value of this exercise. Finally, there is a growing need to measure the impact and quantify the value of from smart specialization.

\section{References}

Afonso O., Monteiro S., Thompson M.J.R. (2010) A growth model for the Quadruple Helix innovation theory (NIPE Working Paper 12), Braga: Universidade do Minho.

Arnkil R., Järvensivu A., Koski P., Piirainen T. (2010) Exploring Quadruple Helix: Outlining user-oriented innovation models (Final Report on Quadruple Helix Research for the CLIQ project, Working Papers 85/2010), Tampere: University of Tampere.

Carayannis E., Sagi J. (2001) New vs old economy: Insights on competitiveness in the global IT industry. Technovation, vol. 21, no 8, pp. 501-514.

Carayannis E.G. (2001) The strategic management of technological learning: Learning to learn and learning to learnhow-to-learn as drivers of strategic choice and firm performance in global, technology-driven markets, Boca Raton, FL: CRC Press.

Carayannis E.G., Campbell D.F.J. (2009) 'Mode 3' and 'Quadruple Helix': Toward a $21^{\text {st }}$ century fractal innovation ecosystem. International Journal of Technology Management, vol. 46, no 3/4, pp. 201-234.

Carayannis E.G., Campbell D.F.J. (2010) Triple Helix, Quadruple Helix and Quintuple Helix, and how do knowledge, innovation and the environment relate to each other? A proposed framework for a transdisciplinary analysis of sustainable development and social ecology. International Journal of Social Ecology and Sustainable Development, vol. 1, no 1, pp. 41-69.

Carayannis E.G., Gonzalez E. (2003) Creativity and innovation = Competitiveness? When, how and why? The International Handbook on Innovation (ed. L.V. Shavinina), Boston: Elsevier Science, pp. 587-605.

Carayannis E.G., Grigoroudis E. (2012) Linking innovation, productivity and competitiveness: Implications for policy and practice. Journal of Technology Transfer, vol. 39, no 2, pp. 199-218.

Carayannis E.G., Grigoroudis E. (2015) Using multiobjective mathematical programming to link national competitiveness, productivity and innovation. Annals of Operations Research (forthcoming).

Carayannis E.G., Grigoroudis E., Sindakis S., Walter C. (2014) Business Model Innovation as antecedent of sustainable enterprise excellence and resilience. Journal of the Knowledge Economy, vol. 5, no 3, pp. 440-463.

Carayannis E.G., Kaloudis A., Mariussen A. (2008) Diversity in the knowledge economy and society: Heterogeneity, innovation and entrepreneurship, Cheltenham: Edward Elgar Publishing.

Carayannis E.G., Meissner D., Edelkina A. (2015) Targeted innovation policy and practice intelligence (TIP2E): Concepts and implications for theory, policy and practice. The Journal of Technology Transfer (forthcoming). DOI: 10.1007/s10961-015-9433-8.

Carayannis E.G., Provance M. (2008) Measuring firm innovativeness: Towards a composite innovation index built on firm innovative posture, propensity and performance attributes. International Journal of Innovation and Regional Development, vol. 1, no 1, pp. 90-107.

Carayannis E.G., Rakhmatullin R. (2014) The Quadruple/Quintuple Innovation Helixes and Smart Specialization Strategies for sustainable and inclusive growth in Europe and beyond. Journal of the Knowledge Economy, vol. 5, no 2, pp. 212-239.

Carayannis E.G., Sagi J. (2002) Exploiting opportunities of the new economy: Developing nations in support of the ICT industry. Technovation, vol. 22, no 8, pp. 517-524.

Carayannis E.G., Sipp C.M. (2010) Why, when and how are real options used in strategic technology venturing? Journal of the Knowledge Economy, vol. 1, no 2, pp. 70-85.

Cervantes M., Meissner D. (2014) Commercialising Public Research under the Open Innovation Model: New Trends. Foresight-Russia, vol. 8, no 3, pp. 70-81.

European Commission (2010) The fifth report on economic, social and territorial cohesion: The future of cohesion, Brussels: European Commission.

European Commission (2012) RIS3 guide, Brussels: European Commission.

European Commission (2014) Smart specialization and Europe's growth agenda, Brussels: European Commission.

Foray D., Goddard J., Beldarrain X.G., Landabaso M., McCann P., Morgan K., Nauwelaers C., Ortega-Argilés R., Mulatero F. (2012) Guide to Research and Innovation Strategies for Smart Specialisations (RIS 3), Brussels: European Commission.

Foray D., Goenaga X. (2013) The goals of Smart Specialization: S3 policy brief series (JRC Scientific and Policy Reports), Brussels: European Commission.

Gackstatter S., Kotsemir M., Meissner D. (2014) Building an Innovation-Driven Economy - The Case of BRIC and GCC Countries. Foresight, vol. 16, no 4, pp. 293-308. 
Guinet J., Meissner D. (2012) Otkrytye innovatsii: effekty dlya korporativnykh strategii, gosudarstvennoi politiki i mezhdunarodnogo «peretoka» issledovanii i razrabotok [Open Innovation: Implications for Corporate Strategies, Government Policy and International R\&D Spillovers]. Foresight-Russia, vol. 6, no 1, pp. 26-36 (in Russian).

Hausmann R., Rodrik D. (2003) Economic development as self-discovery. Journal of Development Economics, vol. 72, no 2, pp. 603-633.

IMD (2003) World competitiveness yearbook 2003, Lausanne: Institute for Management Development.

Jansen J.J.P. (2006) Exploratory innovation, exploitative innovation and performance: Effects of organizational antecedents and environmental moderators. Management Science, vol. 52, no 11, pp. 1661-1674.

Kirzner I.M. (1973) Competition and Entrepreneurship, Chicago: The University of Chicago Press.

Leydesdorff L. (2012) The Triple Helix, Quadruple Helix, ..., and an N-Tuple of Helices: Explanatory models for analyzing the knowledge-based economy. Journal of the Knowledge Economy, vol. 3, no 1, pp. 25-35.

Meissner D. (2012) Ekonomicheskie effekty "peretoka" rezul'tatov nauchno-tekhnicheskoi i innovatsionnoi deyatel'nosti [The Economic Impact of Spillovers from R\&D and Innovation]. Foresight-Russia, vol. 6, no 4, pp. 20-31 (in Russian).

Meissner D. (2014) Approaches for developing national STI strategies. STI Policy Review, vol. 5, no 1, pp. 34-56.

Meissner D. (2015a) Public-Private Partnership Models for Science, Technology, and Innovation Cooperation. Journal of the Knowledge Economy (forthcoming). DOI: 10.1007/s13132-015-0310-3.

Meissner D. (2015b) Measuring Innovation - A Discussion of Innovation Indicators at the National Level (The Swiss Science and Innovation Council Working Paper no 3, SSIC Secretariat Series), Bern: Swiss Science and Innovation Council.

Midtkandal I., Sörvik J. (2012) What is smart specialisation? Nordregio News, no 5. Available at: http://www.nordregio. se/en/Metameny/Nordregio-News/2012/Smart-Specialisation/Context, accessed 14.05.2015.

OECD (2001) Measuring productivity: Measurement of aggregate and industry-level productivity growth, Paris: OECD.

Paas T., Poltimäe H. (2010) A comparative analysis of national innovation performance: The Baltic States in the EU context (Working Paper 78), Tartu: University of Tartu.

Proskuryakova L., Meissner D., Rudnik P. (2015) The use of technology platforms as a policy tool to address research challenges and technology transfer. The Journal of Technology Transfer (online publication). Available at: http:// link.springer.com/article/10.1007/s10961-014-9373-8\#/page-1, accessed 12.02.2016.

Virkkala S., Mäenpää A., Mariussen A. (eds.) (2014) The Ostrobothnian model of smart specialization (Proceedings of the University of Vaasa, Reports 195), Vaasa: University of Vaasa. Available at: http://www.uva.fi/materiaali/pdf/ isbn_978-952-476-577-0.pdf, accessed 26.09.2015.

WEF (2012) The global competitiveness report 2012-2013, Geneva: World Economic Forum. 